\title{
Simplicity and Complexity of the Six-Minute Walk Test
}

\author{
José Antônio Caldas Teixeira ${ }^{\circledR}$ \\ Universidade Federal Fluminense, UFF, Niterói, RJ - Brazil
}

The cardiopulmonary exercise testing (CPET) is known to be the gold standard method for the assessment of functional capacity. However, the method is expensive, often not well tolerated by the patients, and may not be a good strategy to evaluate activities of daily living (ADL). Functional tests are indirect method to assess functional status or functional capacity of an individual to perform ADL and meet their metabolic demands. These tests are considered objective measures that can monitor the clinical course of several diseases as well as responses to interventional therapies.

Walking and running tests were originally developed to evaluate and estimate aerobic physical fitness of healthy individuals and correlate it with maximal aerobic power (peak $\mathrm{VO}_{2}$ ). Balke, in the sixties, followed by Cooper and his 12-minute test, used to evaluate physical performance in healthy subjects, motivated, according to them, by the need of field tests for screening of large populations. These methods showed good correlation with laboratory measurements of aerobic capacity (peak $\mathrm{VO}_{2}$ and anaerobic threshold). ${ }^{1}$

In 1976, McGavin et al., ${ }^{2}$ adapted the Cooper test to an indoor modality of 12-minute walk test to estimate effort tolerance in patients with chronic bronchitis. However, application of this test in clinical conditions was limited by the low functional capacity or low capacity of most patients to maintain a predetermined effort for 12 minutes. In 1982, Butland et al., ${ }^{3}$ started to use shorter exercise periods (6 minutes) in the same population. In these tests, subjects were instructed to walk from one end to the other of a hospital corridor during a six-minute period. The distance covered during this time was then

\section{Keywords}

Heart Failure; Bronchitis, Chronic; Walk Test; Running; Health Status Indicators; Reference Standards. registered. The six-minute walk test (6MWT) was then created; originally used in lung disease patients and then in several randomized clinical trials for evaluation of functional, therapeutic and prognostic factors of heart failure (HF) patients. ${ }^{4}$

The 6MWT has lower personal and technical costs and is easy to perform. More importantly, the walking intensity required during the test is similar to that of everyday day activities, reflecting their ADL. In addition, the intensity of the exercise is determined by the own patient, which is an additional advantage for those with some physical limitations who would not tolerate well the maximum 30-minute CPET. The 6MWT is more reproducible than questionnaires and has been able to detect little, but clinically meaningful changes in patients' functional capacity. ${ }^{5}$ The test can predict the prognosis in HF patients and has been used as an instrument to evaluate the outcome of many interventions. ${ }^{5}$ Absolute and relative contraindications of the $6 \mathrm{MWT}$ are the same of those reported for the maximal effort test.

Therefore, the $6 \mathrm{MWT}$ has been more and more used as an alternative to evaluate functional capacity in patients with HF. The SOLVD showed that the 6MWT is a safe method, and the distance covered during the test has predictive value for mortality and hospitalization rates. ${ }^{4}$ The distance covered is also an independent predictor of mortality and rehospitalizations in HF patients. Studies have reported that distances $\leq$ 300 meters have the worst prognosis in these patients. ${ }^{6}$ Rostagno et al., ${ }^{6}$ showed that event-free survival rates were significantly lower (62\%) in patients who walked a distance shorter than 300 meters, as compared with those who walked an intermediate distance (300-450 meters) and high-performance patients ( $>450$ metros). In severe $\mathrm{HF}$, a distance $<210$ meters was associated with a higher six-month mortality $(50 \%$ vs $20 \%)$ than longer distances.

Mailing Address: José Antônio Caldas Teixeira

Faculdade de Medicina - Departamento de Medicina Clínica - Rua Marquês do Paraná, 303. Postal Code: 24030-210, 2ªndar, Prédio Principal, Centro, Niterói, RJ - Brazil.

E-mail: jacaldas_@hotmail.com 
There is a real possibility of more severe patients perform the 6MWT near or above the first threshold, which is reinforced by its correlation with the $\mathrm{VO}_{2}$ of the anaerobic threshold and of the $\mathrm{VE} / \mathrm{VCO}_{2}$ slope, as demonstrated in studies using gas analyzers during the 6MWT.7 The authors have found mean relative peak $\mathrm{VO}_{2} \geq 85 \%$ of CPET in HF patients, similar to a Brazilian study. ${ }^{8}$ Based on these findings, the $6 \mathrm{MWT}$ has been suggested to be used for prescription of the training intensity in this population. ${ }^{9}$

Despite its high sensitivity, the 6MWT can be influenced by several factors, including motivational and learning factors. However, with adequate standardization of the method, the test can be highly reproducible. Possible sources of variability caused by the procedure itself should be controlled, following guidelines and quality-control programs. ${ }^{5}$

Many factors have been reported to influence the $6 \mathrm{MWT}$ results, including age, sex, height (which influences the step length), body mass (obesity), muscle mass, balance, reduced strength and musculoskeletal changes. All these are potentially determinants of the distance covered. ${ }^{5}$

\section{References}

1. Reybrouck T. Clinical usefulness and limitations of the 6-minute walk test in patients with cardiovascular or pulmonary disease. Chest. 2003;123(2):325-7.

2. McGavin CR, Gupta SP, McHardy GJ. Twelve-minute walking test for assessing disability in chronic bronchitis. Br Med J. 1976;1(6013):822-3.

3. Butland RJ, Pang J, Gross ER, Woodcock AA, Geddes DM. Two-, six-, and 12-minute walking tests in respiratory disease. Br Med J (Clin Res Ed). 1982;284(6329):1607-8.

4. Bittner V, Weiner DH, Yusuf S, Rogers WJ, McIntyre KM, Bangdiwala SI, et al. Prediction of mortality and morbidity with a 6-minute walk test in patients with left ventricular dysfunction. SOLVD Investigators. JAMA.1993;270(14):1702-7.

5. ATS Committee on Proficiency Standards for Clinical Pulmonary Function Laboratories. ATS statement: guidelines for the six-minute walk test. Am J Respir Crit Care Med. 2002;166(1):111-7.

6. Rostagno C, Olivo G, Comeglio M, Boddi V, Banchelli M, Galanti G, et al. Prognostic value of 6-minute walk corridor test in patients with mild
Morais e Rassi, ${ }^{10}$ evaluating determinants of the 6MWT in HF patients, showed important data in a Brazilian population. The authors correlated the distance covered in the $6 \mathrm{MWT}$ with clinical and socioeconomical parameters, comorbidity index, quality of life index, physical activity, depression and anxiety, respiratory functional tests, respiratory muscle strength, and handgrip strength. The authors also reported that age, female sex, vital capacity and dyspnea index for the ADL as the main negative predictors for performance of the ADL. Although a large percentage of patients had chagasic cardiomyopathy $(43 \%)$, their findings corroborate previous studies on patients with HF caused by other conditions. For example, the American Thoracic Society guidelines ${ }^{5}$ reported that these factors, in addition to the severity of underlying disease, musculoskeletal problems and cognitive impairment can reduce the distance covered in the 6MWT.

The $6 \mathrm{MWT}$ is here to stay. Its potential use in functional assessment, in therapeutic interventions and in prognostic estimation should be further explored in HF patients. to moderate heart failure: comparison with other methods of functional evaluation. Eur J Heart Fail. 2003;5(3):247-52.

7. Kervio G, Ville NS, Leclercq C, Daubert JC, Carre F. Cardiorespiratory adaptations during the six-minute walk test in chronic heart failure patients. Eur J Cardiovasc Prev Rehabil. 2004;11(2):171-7.

8. Teixeira JAC, Messias LR, Dias KP, Costa WLB, Cascon RM, Miranda SMR, et al. Estudo por analisador de gases do teste de caminhada de seis minutos na insuficiência cardíaca com fração de ejeção normal. Int J Cardiovasc Sci. 2018;31(2):143-51.

9. Oliveira MF, Zanussi G, Sprovieri B, Lobo DM, Mastrocolla LE, Umeda II, et al. Alternatives to aerobic exercise prescription in patients with chronic heart failure. Arq Bras Cardiol. 2016;106(2):97-104.

10. Morais ER, Rassi S. Determinants of the distance covered during a sixminute walk test in patients with chronic heart failure. Int J Cardiovasc Sci. 2019;32(2)134-142. 